\title{
Evaluasi Implementasi Sistem Manajemen Mutu ISO 9001:2008 di Puskesmas Wilayah Kabupaten Sleman
}

\author{
Sri Nuryati* \\ * Penulis Korespondensi: daroji.inung@gmail.com \\ Dinas Kesehatan Kab. Sleman, Jl Candi Jonggrang No.6 Beran Tridadi Sleman Yogyakarta, Indonesia

\begin{tabular}{|c|c|}
\hline$I N D E X I N G$ & $A B S T R A C T$ \\
\hline Keywords: & This study is a mixed method research, a combination of quantitative and qualitative research \\
\hline Quality; & methods with cross sectional study design. Quantitative research methods to describe the \\
\hline ISO; & health centers, a strong reason to rehabilitate physical structures all health centers. Aspects of the \\
\hline & process: Organizational Management Aspect outcomes: The quality objectives is an indicator of \\
\hline & implementation of QMS ISO 9001: 2008 in health centers $48 \%$ criteria, the criteria of no less than \\
\hline & $8 \%$. The big difference in perceptions of health centers and the Department of Health. in health \\
\hline
\end{tabular}

Kata kunci:

Mutu;

Manajemen:

ISO;

\begin{abstract}
Penelitian ini merupakan penelitian metode campuran, kombinasi metode penelitian kuantitatif dan kualitatif dengan rancangan penelitian cross sectional. Metode penelitian kuantitatif untuk menggambarkan penerapan QMS ISO 9001: 2008. Kebijakan reformasi birokrasi QMS ISO 9001: 2008 di puskesmas, alasan kuat untuk merehabilitasi struktur fisik semua puskesmas. Aspek proses: Manajemen Organisasi Hasil Aspek: Sasaran mutu merupakan indikator keberhasilan, penerapan QMS ISO 9001: 2008. QMS ISO meningkatkan kepuasan pelanggan, penerapan kriteria mutu SMM 9001: 2008 di puskesmas 48\%, kriteria Tidak kurang dari 8\%. Perbedaan besar dalam persepsi pusat kesehatan dan Departemen Kesehatan. Di Puskesmas sudah memenuhi persyaratan pasal 8 dalam pelaksanaan QMS ISO 9001: 2008.
\end{abstract}

(C) 2017 JMMR. All rights reserved

\section{PENDAHULUAN}

Reformasi di bidang kesehatan telah menetapkan visi pembangunan kesehatan Kabupaten Sleman Terwujudnya Sleman Sehat yang Mandiri, Berdaya Saing dan Berkeadilan. Pencapaian kondisi sejahtera dalam arti masyarakat yang keadaan ekonomi, pendidikan dan kesehatan serta spiritualnya baik adalah upaya peningkatan kreatifitas untuk mencapai keunggulan sehingga dapat bertahan dan bersaing dalam berbagai bidang kehidupan dalam pembangunan. ${ }^{1}$

Kabupaten Sleman melalui Dinas Kesehatan dalam melaksanakan kebijakan kesehatan sesuai dengan Sistem Kesehatan Daerah (SKD) yang dituangkan dalam Keputusan Bupati Sleman Nomor: 114/Kep.DH/A/2007 telah mempunyai blue print yang jelas. Ada 5 (lima) hal yang menjadi fokus pengembangan kesehatan di Kabupaten Sleman.

Strategi yang dipergunakan dalam rangka menyelenggarakan misi untuk mencapai Sleman Sehat adalah; Meningkatkan kualitas pelayanan publik melalui peningkatan kapasitas sumberdaya Dinas Kesehatan dengan penerapan good governance, Meningkatkan kualitas pelayanan kesehatan, Penerapan Standart Sistem Manajemen Mutu. Dari data hasil capaian kegiatan sampai dengan awal tahun 2014 sudah ada 23 (dua puluh tiga) puskesmas yang tersertifikasi SMM ISO 9001:2008. Pada akhir tahun 2014 semua puskesmas di Kabupaten Sleman yaitu sebanyak 25 (dua puluh lima) puskesmas diharapkan sudah tersertifikasi SMM ISO 9001:2008.

Implementasi SMM ISO saat ini cukup efektif meningkatkan mutu, salah satunya dengan peningkatan angka kunjungan.

Hasil pemantauan Tim Dinas Kesehatan Kabupaten Sleman pada bulan April tahun 2014 diperoleh informasi permasalahan implementasi SMM ISO 9001:2008 antara lain:

a. Adanya alokasi anggaran yang semakin besar dalam tiap tahunnya untuk pembiayaan survaillan audit maupun resertifikasi SMM ISO 9001:2008, untuk tahun 2014 yaitu sebesar Rp. 894.063.450 ; 
b. Pelaksanaan survaillain audit yang tidak sesuai dengan rencana penjadwalan, akibatnya ketidaksiapan puskesmas;

c. Adanya pelayanan yang tidak sesuai dengan Standart Operasional Prosedur (SOP) yang sudah disepakati;

d. Adanya regulasi pemerintah bahwa fasilitas kesehatan tingkat pertama harus terakreditasi sebagai persyaratan kredensialing kerjasama dengan Badan Penyelenggaran Jaminan Sosial (BPJS), mengakibatkan minat puskesmas untuk meneruskan sertifikasi ISO 9001:2008 menurun.

\section{METODE PENELITIAN}

Penelitian ini merupakan mixed method research, yang merupakan gabungan antara metode penelitian kuantitatif dan kualitatif. Metode penelitian kuantitatif digunakan untuk mengetahui gambaran pengelolaan terhadap implementasi Sistem Managemen Mutu ISO 9001:2008 Sedangkan metode penelitian kualitatif digunakan untuk memperkuat analisis penelitian sesuai dengan fenomena yang diteliti.

Subyek dalam penelitian ini adalah pengelola ISO di Puskesmas, yang terdiri dari Manajemen Representatif (MR) dan Kepala Puskemas. Penelitian mulai dilakukan tanggal 16 Desember 2016 sampai dengan tanggal 3 Maret 2017. Subjek penelitian yang diambil datanya, sebanyak 25 orang sampel dari MR puskesmas diminta untuk mengisi kuesioner terkait implementasi SMM ISO 9001:2008. Wawancara mendalam dengan pejabat struktural yang berwewenang dalam hal pengembangan, pengelolaan, dan penerapan Sistem Management Mutu ISO 9001:2008. Kemudian Obyek penelitian adalah Puskesmas di Kabupaten Sleman.

Penelitian ini dilaksanakan melalui tahapan sebagai berikut:

a) Tahap persiapan, dengan kegiatan: Menyiapkan instumen penelitian dan melakukan pendekatan ke Dinas Kesehatan Kabupaten Sleman dan Puskemas di wilayah Kabupaten Sleman dengan maksud menerangkan maksud penelitian.

b) Tahap pelaksanaan, pengumpulan data kegiatan sebagai berikut: Mengumpulkan data primer

c) Penelitian kuantitatif Pengumpulan data primer dalam penelitian ini secara kuantitatif didapatkan dari kuesioner tentang penerapan SMM ISO 9001:2008 dan tujuan penerapannya, dengan subjek penelitian MR Puskesmas d) Penelitian kualitatif Secara kualitatif data primer diperoleh melalui wawancara mendalam, kepada subjek penelitian Kepala Puskesmas.

Mengumpulkan data sekunder Pengumpulan data dilaksanakan dengan cara observasi dan penelusuran terhadap dokumen-dokumen penerapan SMM ISO 9001:2008. Analisis Data yang diperoleh dikumpulkan dan diolah dengan serangkaian proses

analisis kualitatif, Pengolahan data dilakukan dengan tahapan berikut:

Data yang dijaring dengan kuesioner yang merupakan data kuantitatif, dianalisis secara kuantitatif melalui analisis diskriptif yang berupa perhitungan rata-rata dan perhitungan persentase. Cara menghitung nilai setiap butir pertanyaan adalah sebagai berikut: dalam penelitian ini jumlah butir pertanyaan dalam instrumen ada 48 nomor. Jumlah responden ada 25 orang. Skor tertinggi tiap butir soal adalah 4. Jadi jumlah skor tertinggi dalam setiap butir soal untuk total responden adalah 100. Skor terendah dalam setiap butir soal untuk total respoden adalah 25 .

$$
\begin{aligned}
\text { NB: } & \sum \text { SH X100\% } \\
& \sum \text { SK }
\end{aligned}
$$

Dimana NB : Nilai Skor Butir

$\begin{array}{ll}\sum \text { SH } & : \text { jumlah skor hitung } \\ \sum \text { SK } & : \text { skor tertinggi }=25 \times 4=100\end{array}$

Metode pengukuran dengan mengunakan kriteria skala linket.

$$
\begin{array}{ll}
\text { Sangat Baik } & \text { : Nilai } 4 \\
\text { Baik } & \text { : Nilai } 3
\end{array}
$$

Tidak Baik : Nilai 2

Sangat Tidak Baik : Nilai 1

b. Melakukan triangulasi untuk mengurangi kesalahan dalam pengumpulan data dan menjaga validitas dengan melihat dan membandingkan hasil wawancara dengan data sekunder di Dinas Kesehatan Kabupaten Sleman.

\section{HASIL DAN PEMBAHASAN}

Kelompok responden dari kalangan Quality Manajement Reperesentatif (QMR), sebanyak 25 (dua puluh lima) puskesmas dilibatkan dalam survei untuk memberikan gambaran tentang SMM ISO 9001:2008. 


\section{Aspek Struktur/Input Puskesmas}

Aspek fisik dan bangunan berikut adalah tanggapan dari responden terkait dengan pemenuhan standar SMM ISO 9001:2008, Kondisi fisik dan bangunan hampir semua puskesmas di wilayah Kabupaten Sleman sudah sesuai prototipe dari Dinas Kesehatan, dengan skor sangat baik $(100 \%)$.

Puskesmas mempunyai inventaris ambulans sebagai fasilitas pendukung operasional pelayanan untuk pasien yang membutuhkan. Skor untuk kesesuaian mobil Ambulan dengan standar sebesar 75\%. Inventaris ambulans setiap puskesmas rata-rata 2 (dua) unit mobil ambulans. Kendala di lapangan, tidak semua puskesmas mempunyai tenaga Sopir, sehingga perlu penambahan tenaga sebagai pengemudi di puskesmas.

Terkait dengan pemenuhan standar ISO 9001:2008 pada aspek input khususnya pemenuhan fasilitas dan peralatan dimintakan pendapat melalaui wawancara mendalam. Pada umumnya informan menyatakan bahwa SMM ISO 9001:2008 membawa dampak positif khususnya pemenuhan fasilitas dan peralatan yang selama ini sulit diadakan menjadi harus diadakan sesuai permintaan standar.

Petugas terhadap peningkatan mutu merupakan penggerak utama berjalannya SMM ISO 9001:2008. Tabel di bawah ini menjelaskan capaian kesesuaian dari aspek komitmen petugas. Struktur pengelola SMM ISO 9001:2008 puskesmas, sudah ada pembagian tugas antara Kepala puskesmas dengan Quality Management Representative (QMR), yang bertanggung jawab terhadap implementasi SMM ISO 9001:2008.

Aspek perencanaan dan logistik menempati satu klausul khusus dalam SMM ISO 9001:2008.

\section{Aspek Proses}

Aspek review dokumen, kebijakan bukanlah suatu dokumen yang bersifat tetap, bahkan harus dilakukan review untuk kepentingan evaluasi seara berkala. Adanya review dokumen merupakan indikasi adanya continous improvement di puskesmas. Dokumen apa saja yang membutuhkan review berkala dan sejauh mana puskesmas telah menjalankannya.

Pada awal penerapan sistem manajemen mutu Kepala puskesmas menetapkan kebijakan mutu puskesmas. Sebagian besar kebijakan mutu puskesmas masih relevan hingga saat ini. Aspek adminstratif dalam SMM ISO
9001:2008 ditekankan pada kontrol dokumen.

Aspek continous improvement masih perlu peningkatan, dimana pasca asesmen seringkali tidak dilanjutkan secara rutin. Proses perbaikan temuan kadangkala dilaksanakan menjelang proses audit saja.

Audit interal sudah berjalan rutin setiap enam bulan sekali. Apabila ada permasalahan yang belum bisa terpecahkan, masuk dalam materi bahasan tinjauan manajemen.

Audit ekternal sudah berjalan secara periodik enam bulan sekali. Auditor ekternal dari lembaga independen,yang mempunyai lisensi sebagai lembaga sertifikasi, kompeten dan profesional.

Disamping adanya efek positif yang dihasilkan dari implementasi SMM ISO 9001:2008 berupa komitmen untuk meningkatkan mutu dan keselamatan, ada hal menarik lainnya dimana kesadaran untuk peningkatan mutu didorong karena adanya penilaian oleh pihak ketiga yakni lembaga sertifikasi. Meskipun pengawasan mutu telah menjadi program rutin Dinas Kesehatan Sleman, namun penilaian oleh pihak eksternal ternyata memiliki daya ungkit lebih dalam upaya peningkatan mutu pelayanan Puskesmas.

\section{Aspek Outcome}

Aspek sasaran mutu puskesmas sebagai indikator pengukuran dalam sistem manajemen mutu. Dalam proses penyusunan sasaran mutu melibatkan semua unit pelayanan yang ada dipuskesmas. Permasalahan yang ada di masingmasing unit disusun berdasarkan prioritas dan sebagai bahan masukan dalam penentuan sasaran mutu. Kegiatan sasaran mutu dan kepuasan pelanggan di puskesmas disajikan dalam table 4.12. Aspek Sasaran Mutu Kepuasan Pelanggan

Persepsi Kepala Puskesmas tentang Keberlangsungan implementasi SMM ISO 9001:2008 pasca regulasi JKN (Jaminan Kesehatan Nasional)

Penerapan SMM ISO yang sudah berjalan cukup lama, dari aspek psikologis menimbulkan kejenuhan. Dampak dari anggaran adalah harus mengurangi biaya operasional yang lain untuk mendukung kegiatan SMM ISO di puskesmas. Sisi positifnya adalah karena intervensi pihak luar memiliki daya ungkit lebih tinggi.

Wawancara juga dilakukan terhadap Kepala Bidang Pelayanan Medik Dinas Kesehatan Sleman. Berdasarkan dengan regulasi tentang JKN, pemberi pelayanan kesehatan tingkat pertama, dalam rangka pelayanan kepada pelanggan 
dengan system kapitasi, puskesmas wajib terakreditasi. Meskipun kepala puskesmas menghendaki menggunakan satu sistem saja yakni akreditasi namun Dinas Kesehatan sepertinya menginginkan hal yang berbeda.

Persepsi dari Puskesmas tentang Keberlangsungan Implementasi SMM ISO 9001:2008 Pasca Regulasi Akreditasi Puskesmas (Fasilitas Kesehatan Tingkat Primer harus terakreditasi).

Pada sesi wawancara terungkap adanya persepsi dari puskesmas yang menyatakan tujuan dari SMM ISO 9001:2008 dan akreditasi adalah sama untuk menstandarkan sistem pelayanan di puskesmas. Sebaiknya salah satu saja.

Pada aspek efisiensi, akreditasi lebih efisien karena bersifat menyeluruh. Jika implementasi keduanya adalah sebuah pilihan, maka perlu upaya kolaborasi antara SMM ISO 9001:2008 dengan Akreditasi Puskesmas.

\section{Evaluasi Implementasi Sistem Manajemen Mutu ISO} 9001:2008 Puskesmas dari aspek Sruktur:

Berdasarkan hasil yang terungkap dalam penelitian ini, Dinas Kesehatan Kabupaten Sleman menerapkan sistem manajemen mutu merupakan upaya dalam reformasi birokrasi. Menurut Djoko Wijono (2000), menyatakan bahwa hubungan mutu dan aspek-aspek dalam pelayanan kesehatan dan cara-cara peningkatan mutu pelayanan kesehatan dapat melalui pendekatan institusional atau individu.2 Menurut Prof. A Donabedian, dalam Djoko Wijono (2000), ada 3 (tiga ) pendekatan evaluasi mutu aspek: struktur, proses, output. Komponen struktur untuk kesesuaian sumber daya listrik dengan kebutuhan. ${ }^{2}$

1. Aspek struktur untuk sarana fisik perlengkapan \& peralatan: kondisi fisik bangunan skor $100 \%$. tata ruang pelayanan skor $74 \%$. Hal ini merupakan dampak positif bagi jajaran Dinas Kesehatan Kabupaten Sleman, karena penerapan SMM ISO 9001:2008 dapat dijadikan alasan kuat untuk advokasi ke Pemerintah Daerah guna memperbaiki fasilitas bangunan di puskesmas. Hal ini sesuai yang diungkapkan Wijayanti (2008), puskesmas yang memilik ruang pelayanan yang lebih banyak, diharapkan pelayanan bisa berjalan lebih cepat. ${ }^{3}$ Aspek utilitas dan prasarana, kapasitas daya listrik $67 \%$, kondisi sumber listrik cadangan $69 \%$, kesesuaian daya listrik dengan kebutuhan 68\%. Kebutuhan daya listrik setiap tahunnya bertambah, antara lain disebabkan adanya penambahan barang inventaris penunjang pelayanan klinis maupun peralatan pendukung administrasi. Penerapan sistem manajemen mutu ISO 9001:2008 merupakan langkah perbaikan mutu baik sumber daya maupun kegiatan pelayanan organisasi pelayanan kesehatan. Berkaitan dengan hal tersebut, hasil penelitian (Wijayanti, 2008) menyebutkan bahwa semua karyawan atau petugas harus memiliki komitmen yang kuat dalam berusaha memberikan pelayanan kesehatan yang baik. ${ }^{3}$ Integrasi system informasi dengan Dinas Kesehatan belum diterapkan untuk semua jenis laporan skor $68 \%$. Peralatan non medis untuk pelayanan puskesmas bisa dianggarkan melalui anggaran puskesmas, sehingga dalam mekanisme perencanaan, harus memperhitungkan kebutuhan dalam tahun berjalan maupun tahun yang akan datang. Kendala di lapangan, tidak semua puskesmas mempunyai tenaga Sopir, sehingga perlu penambahan tenaga sebagai pengemudi di puskesmas. Dari hasil penelitian Pongpirul K, et al, (2006), Integrasi dan pemanfaatan informasi menduduki peringkat tertinggi sebagai suatu hambatan yang besar. $^{21}$

2. Aspek Organisasi \& Manajemen Struktur organisasi ISO di puskesmas, disusun berdasarkan Struktur organisasi puskesmas. Setiap unsur mempunyai Tupoksi masing-masing yang harus dilaksanakan dalam rangka menjalankan SMM ISO 9001:2008. Hal ini sesuai dengan yang dinyatakan Suryanto, dkk (2011) bahwa ada hubungan positif yang sangat signifikan antara kepuasan kerja dan persepsi perawat tentang kepemimpinan dengan kinerja perawat pasca sertifikasi ISO 9001/2008. ${ }^{4}$ Dalam penelitian Enny WM (2015), 'Total manajemen mutu dan lingkungan kerja memiliki dampak positif dan signifikan terhadap kepuasan kerja karyawan. ${ }^{17}$ Management Representative (MR), mensosialisasikan kebijakan mutu dan memelihara sistem menajamen mutu yang dijabarkan dalam pedoman mutu, prosedur mutu dan prosedur tetap (protap). Pada penelitian Kusumaningtyas, Puskesmas Pagu dengan Sertifkasi ISO yang mempunyai SOP telah melakukan aktifitas kerja sesuai dengan proses SOP yang ditetapkan. Memastikan agar penerapan mutu dilakasanakan secara efektif dan efisien untuk memenuhi persyaratan ISO 9001:2008. Melaporkan penerapan sistem manajemen mutu kepada Kepala Puskesmas. Pada penelitian Susilawati (2013) wujud keterlibatan personel adalah dengan dilibatkannya semua warga 
sekolah dalam berbagai kegiatan sehingga ketercapain tujuan merupakan hasil koordinasi semua bagian dari top hingga bottom, mengimplementasikan tugas sesuai dengan Tupoksi, serta prosedur yang telah ditetapkan. Melakukan komunikasi internal sesuai media komunikasi yang telah ditetapkan. ${ }^{5}$

3. Aspek Keuangan (Biaya Mutu), komitmen yang kuat dari Pemerintah Daerah ikut andil dalam pendanaan yang mendukung kegiatan SMM ISO 9001:2008. Melalui strategi tersebut Dinas Kesehatan Kabupaten Sleman berhasil melakukan advokasi kepada Tim Pengesahan Kegiatan Anggaran Daerah Kabupaten Sleman. Pada penelitian Maharani (2007), ${ }^{15}$ rumah sakit dari 19 rumah sakit yang menjadi responden menjalankan langkah-langkah perbaikan mutu yang berkelanjutan secara konsisten. Rumah sakit yang tidak menjalankan langkah-langkah perbaikan mutu disebabkan karena permasalahan biaya atau komitmen dari setiap pihak dalam rumah sakit. ${ }^{6}$ Dalam penelitian Rajkovic D, Integrasi sistem manajemen kualitas, lingkungan, kesehatan dan manajemen risiko sertabtanggung jawab sosial korporasi bisa diterapkan korporasi pendekatan untuk mengurangi biaya. ${ }^{19}$

4. Aspek Sumber Daya Manusia, keterlibatan personel merupakan prinsip yang ketiga dari pelaksanaan SMM ISO 9001:2008. Dari penelitian Widyastuti (2015), secara bersama-sama karyawan dan pimpinan mampu memaksimalkan peran dalam penerapan Quality Mananajemen System. ${ }^{7}$ Dari hasil penelitian Djasri (2006), keterlibatan staf dalam semua tingkatan untuk aktif dalam melihat peluang dalam meningkatkan kompetensi, pengetahuan dan pengalaman. ${ }^{8}$ Secara berkala puskesmas merencanakan review menjalin komitmen mutu dan merencanakan kegiatan tahun berikutnya. Hal ini sesuai dengan yang dinyatakan Maharani (2008) kunci keberhasilan dari penerapan SMM ISO 9000 adalah komitmen semua pihak baik dari pihak atasan sampai dengan bawahan.6 Hal ini di sadari dan dipahami bahwa SMM ISO 9000 bukanlah suatu alat ajaib yang bisa merubah sesuatunya tanpa perjuangan semua pihak. Dalam penelitian Susilawati et al. (2013), wujud keterlibatan personel adalah dengan dilibatkannya semua warga sekolah dalam berbagai kegiatan sehingga, ketercapain tujuan merupakan hasil koordinasi koordinasi semua bagian dari top hingga bottom. Hal ini sesuai dengan penelitian Primiani (2015), selain itu komitmen dari pimpinan untuk dapat mendukung kegiatan penerapan Total Quality Manajemen sangat diperlukan. ${ }^{5}$
5. Aspek sumber daya lainnya, pengelolaan sumber daya merupakan klausul keenam dari delapan klausul sebagai persyaratan dalam penerapan SMM ISO 9001:2008. Dari aspek perencanaan capain skor sudah sangat baik, hal ini dikarenakan sudah adanya mekanisme usulan berjenjang dengan format dan pedoman baku (SHBJ, RPK), dari puskesmas ke Dinas Kesehatan.

\section{Evaluasi Implementasi Sistem Manajemen Mutu ISO 9001:2008 Puskesmas dari Aspek Proses:}

1. Aspek Pengendalian Dokumen, merupakan aspek yang masuk dalam klausul 4 (empat) Persyaratan dokumentasi. Dari hasil penelitian ini, diketahui bahwa dari komponen review pedoman mutu mencapai skor $60 \%$ kategori cukup, hal ini dikarenakan pedoman mutu yang ada masih relevan dan belum perlu mereview pedoman mutu. Belum ada perubahan ruang lingkup penerapan SMM ISO 9001:2008. Dalam penelitian Heuvel et al. (2006) ISO sering dianggap identik dengan birokrasi. Faktanya di rumah sakit itu, karena sejumlah alasan, seperti regulasi pemerintah, pemeriksaan kesehatan harus mempertahankan tingkat yang cukup untuk registrasi dan dokumentasi. Di rumah sakit kami ini mengakibatkan sejumlah besar dan tidak terkendali dokumen dengan banyak duplikat dengan perbedaan hanya kecil yang relatif tidak dapat di akses. ${ }^{10}$ Sesuai dengan penelitian Mitreval E, Menerapkan strategi ini TQM baru berarti merancang sistem mutu kokoh didokumentasikan yang mencakup setiap proses bekerja di sebuah perusahaan dan muncul sebagai dasar yang diperlukan untuk penggunaan sukses kontrol statistik proses dan kerja sama tim. ${ }^{18}$

2. Audit internal berkala $90 \%$, membuat tindak lanjut hasil audit ekternal 77\%, feedback audit internal 90\%. Dari hasil penelitian Ekowati (2007), tingkat pemahaman dan kepatuhan penanggung jawab unit maupun pelaksana dalam implementasi QMS 9001:2000 dapat dikategorikan cukup baik. Kondisi ini hanya bermakna pada system audit yang dilakukan secara berkala. ${ }^{15}$ Kegiatan audit internal maupun ekternal sudah rutin dilaksanakan sebagai kegiatan evaluasi. Hal ini sesuai yang dinyatakan Susilawati et al. (2013), tindakan evaluasi ini bisa dengan audit internal maupun management review. ${ }^{5}$ Dari hasil penelitian dengan observasi dokumen 
terungkap bahwa, 8 (delapan) klausul sebagai persyaratan dalam penerapan SMM ISO 9001:2008 sudah dipenuhi Puskesmas di wilayah Kabupaten Sleman, yakni: 1) Lingkup Penerapan, mencakup pelayanan yang ada di puskesmas; 2) Acuan Normatif, acuan yang digunakan; 3) Istilah dan definisi, istilah dan definisi yang digunakan; 4) Sistem Manajemen Mutu, disesuaikan dengan Pedoman Mutu, Persyaratan Dokumen, Rekaman Kegiatan yang ada dan pengendalian dokumen; 5) Tanggung Jawab Manajemen, meliputi antara lain komitmen manajemen; 6) Pengelolaan Sumber Daya, meliputi sumber daya manusia, sumber daya lainnya, sarana prasarana; sudah dijalankan guna mendukung pelayanan di puskesmas; 7) Realisasi Produk, meliputi: rencana realisasi layanan, proses yang berhubungan dengan pelanggan, pengadaan barang dan jasa, pengendalian operasional layanan, pengendalian alat ukur dan alat pantau.; 8) Pengukuran, Analisis dan Perbaikan, dilaksanakan dari berbagai komponen baik puskesmas, pelanggan, monitoring dari Dinas Kesehatan selaku instansi pembina. Dari hasil penelitian Akhyar (2014), diperlukan adanya kesungguhan dari warga sekolah secara bersama, sadar dan berkeinginan kuat untuk maju. ${ }^{12}$ Dalam pelaksanaan implementasi SMM ISO 9001:2008 sudah berlandaskan 8 (delapan) prinsip manajemen tersebut adalah: 1) Fokus pada pelanggan, mengidentifikasi dimensi mutu pelanggan; 2) Kepemimpinan, komitmen manajemen untuk meningkatkan serta memperbaiki kinerja SMM; 3) Keterlibatan personel, dalam semua kegiatan SMM dan koordinasi semua unit; 4) Pendekatan proses, adanya prosedur dalam SMM ISO 9001:2008; 5) Pendekatan system, dibuktikan dengan pedoman -pedoman yang sudah disusun sesuai struktur dokumen; 6) Pengambilan keputusan dengan fakta, peran dari manajemen dalam pengambilan keputusan, memperhatikan saran dan masukan dari bawahan; 7) Perbaikan berkelanjutan, adanya capaian indikator sasaran mutu yang dievaluasi secara periodik dan tindak lanjutnya; 8) Hubungan pemasok, mengidentifikasi persyaratan pelanggan dan prosedur penangan keluhan, Dari hasil penelitian Khalili A, SMM (Sistem Manajemen Mutu) adalah inisiatif yang jelas dengan tujuan meningkatkan efektivitas dan efisiensi. $^{20}$

\section{Evaluasi Implementasi Sistem Manajemen Mutu ISO} 9001:2008 Puskesmas dari Aspek Outcome:

1. Aspek sasaran mutu, dari penelitian ini diketahui: pencapain skor untuk sasaran mutu puskesmas sesuai dengan kebutuhan 90\%, Analisa sasaran mutu di feedback ke unit dan ditindaklanjuti skor 100\%. Dalam penentuan sasaran mutu berpedoman pada standar pelayanan minimal (SPM). Tingkat capaian sasaran mutu merupakan indikator dari keberhasilan penerapan SMM ISO 9001:2008. Sasaran mutu juga merupakan solusi untuk target yang belum tercapai. Hal ini sesuai dengan hasil penelitian Susilawati et al. (2013), pencapaian sasaran mutu merupakan indikator sebuah keberhasilan dari pelaksanaan SMM ISO 9001:2008.5 Dari penelitian Hadi (2005) dalam Haryanto (2014), SMM adalah bagian sistem manajemen organisasi yang mefokuskan perhatiannya pada pencapain hasil, berkaitan dengan sasaran mutu, untuk memuaskan kebutuhan , harapan dan persyaratan pihak yang berkepentingan. ${ }^{13}$

2. Aspek kepuasan pelanggan, pengolahan keluhan pelangggan masih direkap manual belum ada sitem database keluhan pelanggan. Dari hasil penelitian Kafidzin, Setelah membentuk unit pelayanan keluhan pasien atau customer care maka langkah selanjutnya adalah membuat system penanganan keluhan.14 Perlu inovasi dalam hal ini untuk diterapkan di puskesmas wilahyah Kabupaten Sleman. Dari hasil penelitian di ketahui, melaksanakan survei kepuasan pelanggan berkala secara rutin skor $86 \%$. Melakukan pengolahan hasil survei $100 \%$. Setiap puskesmas sudah melaksanakan survei kepuasan (IKM) indeks kepuasan masyarakat rutin setiap 6 (enam) bulan sekali. Hasil rekap di Dinas Kesehatan tahun 2015 semester pertama 78,7,\% semester kedua 79,52. Hal ini seperti diungkapkan Qolbi (2014), sistem manjemen mutu ISO 9001:2008 telah berhasil meningkatkan kepuasan pelanggan mengenai hal dalam pemenuhan keinginan dan kebutuhan pelanggan bagi pengguna jasa pelayanan. Hal ini sejalan dengan prinsip SMM ISO 9001:2008 bahwa tiap organisasi harus mampu memenuhi dan berusaha melebihi harapan pelanggan. ${ }^{15}$ Evaluasi penerapan SMM ISO puskesmas $48 \%$ dengan kriteria baik, $36 \%$ cukup, $8 \%$ kurang dan $8 \%$ 
dengan kriteria kurang. Dari hasil penelitian diperoleh informasi bahwa komitmen manajemen dan continuous improvement masih perlu peningkatan terutama pasca assessment baik internal maupun ekternal. Kecenderungan perbaikan hanya dilakukan pada saat menjelang audit saja.

Keberlangsungan Implementasi Sistem Manajemen Mutu ISO 9001:2008 Puskesmas di Wilayah Kerja Dinas Kesehatan Kabupaten Sleman pasca Regulasi Jaminan Kesehatan Nasional/JKN. Berdasarkan dengan regulasi tentang JKN, dalam rangka pelayanan kepada pelanggan dengan sistem kapitasi, puskesmas wajib terakreditasi. Hasil wawancara yang dilakukan terhadap Kepala Bidang Pelayanan Medik Dinas Kesehatan Sleman, meskipun kepala puskesmas menghendaki menggunakan satu sistem saja yakni akreditasi namun Dinas Kesehatan sepertinya menginginkan hal yang berbeda. Pada aspek efisiensi, akreditasi lebih efisien karena bersifat menyeluruh atau komplit (Adminstrasi Manajemen, UKM \& UKP).

Keberlangsungan Implementasi Sistem Manajemen Mutu ISO 9001:2008 Puskesmas di Wilayah Kerja Dinas Kesehatan Kabupaten Sleman pasca Regulasi Akreditasi Puskesmas:

Menurut Peraturan Menteri Kesehatan Nomor 75 tahun 2014, dalam upaya meningkatkan mutu pelayanan, puskesmas wajib diakreditasi secara berkala paling sedikit 3 (tiga) tahun sekali. ${ }^{16}$

Berdasarkan hasil dalam penelitian ini terungkap adanya persepsi dari puskesmas yang menyatakan tujuan dari SMM ISO 9001:2008 dan akreditasi adalah sama untuk menstandarkan sistem pelayanan di puskesmas. Penerapan sistem standar wajib, kalau bisa salah satu saja, karena yang ada di SMM ISO 9001:2008 sudah ada di akreditasi. Hal ini sesuai dengan yang dinyatakan Shaw, et al (2010), bahwa tidak ada perbedaan substansial antara akreditasi dan sertifikasi ISO.9 Konfirmasi hasil analisis statistik ada perbedaan signifikan dengan sistem audit ekternal, tampak jelas kualitas stuktur dan prosedur.

\section{SIMPULAN}

Berdasarkan hasil pembahasan seperti yang diutarakan di atas dapat di tarik kesimpulan sebagai berikut; Evaluasi Implementasi Sistem Manajemen Mutu ISO 9001:2008 Puskesmas di Wilayah Kerja Dinas Kesehatan Kabupaten Sleman: Kebijakan reformasi birokrasi dengan penerapan SMM ISO 9001:2008 di puskesmas, sangat menguntungkan Dinas Kesehatan Kabupaten Sleman, karena menjadi alasan kuat untuk merehabilitasi bangunan fisik semua puskesmas. Sarana prasarana terpenuhi, yang belum sinkron adalah kebutuhan kapasitas daya listrik dengan perencanaan penambahan peralatan penunjang pelayanan. Sistem informasi puskesmas sudah berjalan, namun integrasi dengan sistem informasi Dinas Kesehatan belum semuanya bisa diakses melalui sistem, terutama untuk laporan bulanan (LB) program. Kendala di lapangan, tidak semua puskesmas mempunyai tenaga sopir, sehingga perlu penambahan tenaga sebagai pengemudi di puskesmas.

Dari aspek proses, Manajemen Organisasi di Puskesmas sudah memenuhi klausul- klausul persyaratan dalam implementasi SMM ISO 9001:2008 sebanyak delapan klausul prinsip manajemen mutu. Implementasi SMM ISO 9001:2008 sudah berjalan dalam rentang waktu yang panjang, sehingga muncul kejenuhan di tingkat puskesmas, berdampak pada fluktuasi komitmen.

Dari aspek outcome/luaran, Dalam penentuan sasaran mutu berpedoman pada standar pelayanan minimal (SPM). Sasaran mutu juga merupakan solusi untuk target yang belum tercapai. Sistem manjemen mutu ISO 9001:2008 telah berhasil meningkatkan kepuasan pelanggan. Secara umum penerapan SMM ISO 9001:2008 di puskesmas empat puluh delapan persen kriteria baik, duabelas persen cukup, delapan persen sangat baik dan dengan kriteria kurang sebesar delapan persen.

Keberlangsungan implementasi SMM ISO 9001:2008 di Puskesmas Wilayah Kerja Dinas Kesehatan Kabupaten Sleman Pasca Regulasi JKN dan Akreditasi Puskesmas menunjukkan adanya perbedaan persepsi antara Puskesmas dan Dinas Kesehatan.

\section{DAFTAR PUSTAKA}

1. Dinas Kesehatan Kabupaten Sleman. 2013. Profil, Kesehatan Sleman, Yogyakarta.

2. Wijono D, 2000. Manajemen Mutu Pelayanan Kesehatan, Jakarta: Airlangga University Press

3. Baraba Wijayanti.2008. Implementasi Total Quality Management: Studi Pada Puskesmas di Kabupaten Sleman Dengan Sertifikat ISO 9001:2000, Universitas Gadjah mada Yogyakarta.

4. Suryanto, Sutomo, Setyawati, 2011, 'Kepuasan Kerja dan Persepsi Perawat Tentang Kepempinan dengan Kinerja Perawat Pasca Sertifikasi ISO 9001:2008, 'Jurnal Manajemen Pelayanan Kesehatan, vol. 14, h. 36-43.

5. Susilawati, Sukirman, Sri Sumaryati, 2013, 'Implementasi Sistem Manajemen Mutu ISO 
9001:2008 Di SMA Batik 1 Surakarta,' Jupe UNS , vol. 1, no. 2, h.1-12.

6. Maharani, C. 2009, Sistem Manajemen Mutu ISO 9000 sebagai alat peningkatan kualitas organisasi pelayanan kesehatan, 'Jurnal Kesehatan Masyarakat,' Kesmas 5 (1), h. 40-47.

7. Widyatuti N, 2015. 'Pengaruh Penerapan Quality Manajemen System’ Terhadap Kualitas Sumber Daya Manusia pada PT. Casuarina Harsenindo Bekasi. 'Jurnal Kajian Bisnis vol.23 no.1 h.40-51

8. Hanevi Jasri, 2006, ‘ Penerapan Clinical Governance Melalui ISO 9000: Studi Kasus Di Dua RSUD Provinsi Jawa Timur,' Jurnal Manajemen Pelayanan Kesehatan, vol.9, h.121-128.

9. Charles S, Oliver G, Nuria Mora, Rosa S, 2010, 'Accreditation and ISO certification: do they explain differences in quality management in European hospitals, 'International Journal for Quality in Health Care, vol 22, no. 6: hh. 445-451

10. Jaap van den H, Lida K, Ad J.J.C. B,Marc B, Monique E.M. 2006, 'An ISO 9001 Quality Management System in a Hospital Bureaucracy or Just Benefits, 'Internasional Journal of Health Care Quality Assurance, vol. 18, no. 5: hh. 361-369.

11. Ekowati D, 2007 'Pengaruh Implementasi Quality Manajemen System 9001:2000 Terhadap Kinerja RS Duren Sawit,'Jurnal Kesehatan Masyarakat Nasional, vol. 2 no.3 Desember.

12. Akhyar Y, 2014. 'Manajemen Mutu Terpadu, 'Jurnal Potensia vol.13 Edisi 1 Januari-Juni’.

13. Didik Haryanto, 2014, 'Analisis Persiapan Penerapan Sistem Manajemen Mutu ISO 9001:2008 Pada Instalasi Farmasi Rumah Sakit $d r$. Soehadi Prijonegoro Kabupaten Sragen.

14. Rohmad K, Analisis Implementasi Total Quality Management (TQM) Pelayanan Rawat Inap Di RS Kumalasiwi Mijen Kudus, Dikases 2 Februari 2017

15. Yahdi Qolbi, 2014, 'Sistem Manajemen Mutu ISO 9001:2008 Dalam Peningkatan Mutu Pelayanan dan Kepuasan Pelanggan Di Dinas Kesehatan Kota Tarakan,' eJournal Ilmu Pemerintahan, 2 (4), h. 3119 3130.

16. Peraturan Menteri Kesehatan Nomor 75 Tahun 2014, Pusat Kesehatan Masyarakat, Jakarta. Primiani C, Ariani D, 'Total Quality Management dan Service Quality Dalam Organisasi Pendidikan Tinggi, ‘ Cakrawala Pendidikan Juni 2015 tahun XXIV no. 2.

17. Enny WM, 2015,' Effect of ISO 900-2008 QMS, Total Quality Management and WorkEnvironment on Job
Satisfaction and Employee Performance at Pt. Mount Dreams Indonesia in Gresik. 'The International Journal Of Business \& Management (ISSN 2321 8916).

18. Mitreval E, Filipovski O, 'Proposal Methodologi Of The Sub System Internasional Standardization As Part Of TQM System, 'International Journal for Quality research UDK- 378.014.3(497.11) Short Scientific Paper (1.03).

19. Rajkovic D, Aleksic M, 'Corporative Motives on Implementation of Integrated Management System (IMS), 'International Journal for Quality research UDK- 378.014.3(497.11)Short Scientific Paper (1.03).

20. Khalili A, Md, Ismail Y, A.N.M. Karim, 'Integration of Lean Manufacturing and Quality Management System Through Structural Equation Modeling, ‘ Department of Manufacturing and Material Engineering International Islamic University Malaysia (IIUM), Gombak, Kuala Lumpur 53100, Malaysia.

21. Pongpirul K, Sriratanaban J, Asavaroengchai S, Thammatach-Aree J, Laqitthi P, 'Comparison of health care professionals'and surveyors' opinions on problems and obstacles in implementing quality management system in Thailand:a national survey, 'International Journal for Quality in Health Care 2006; Volume 18, Number 5: pp. 346-351. 